\title{
SPIN LABELLED HEMOGLOBIN-BASED OXYGEN CARRIERS (HBOC): PREPARATION AND EVALUATION OF IN VIVO / IN VITRO STABILITY
}

\author{
RADU SILAGHI-DUMITRESCU ${ }^{a, *}$, CRISTINA GRUIAN ${ }^{b}$, \\ CRISTINA PUSCAS ${ }^{a}$, ALEXANDRA SIMON ${ }^{a}$, EVA FISHER-FODOR ${ }^{c}$, \\ VLAD AL. TOMA ${ }^{\mathrm{d}, \mathrm{e}}$, ANCA FARCAS $^{\mathrm{d}, \mathrm{e}}$, IOANA ROMAN ${ }^{\mathrm{d}}$, \\ VIOLETA-FLORINA SCURTUa, AMR A.A. ATTIA ${ }^{a}$, \\ GRIGORE DAMIAN ${ }^{f}$
}

\begin{abstract}
Site-directed spin labeling and EPR characterization (continuous wave as well as DEER) of two blood substitute candidates is described for the first time: glutaraldehyde-polymerized bovine hemoglobin and the related hemoglobin-albumin copolymer. In vitro, with two different types of cell cultures, these spin-labeled candidates are relatively stable; however, they appear to be rapidly reduced in vivo, most likely via removal or reduction of the spin label (as opposed to removal of the blood substitute candidate from the circulatory system altogether).
\end{abstract}

Keywords: hemoglobin, albumin, blood substitute, HBOC, EPR, spin label, MTSSL, in vivo, cell culture, free radical

a Department of Chemistry and Chemical Engineering, "Babes-Bolyai" University, 11 Arany Janos street, Cluj-Napoca 400028, Romania

b Institute for Interdisciplinary Research on Bio-Nano-Systems, "Babes-Bolyai" University, 11 Arany Janos street, Cluj-Napoca 400028, Romania

c Ion Chiricuta Cancer Institute - Comprehensive Cancer Center, 34-36 Republicii street, ClujNapoca 400015, Romania

d Institute of Biological Research, "Babes-Bolyai" University, 48 Republicii street, Cluj-Napoca 400015, Romania

e National Institute for Research and Development of Isotopic and Molecular Technologies, 400293 Cluj-Napoca, Romania

${ }^{f}$ Department of Physics, Babes-Bolyai University, Cluj-Napoca 400028, Romania

*Corresponding author: rsilaghi@chem.ubbcluj.ro 
R. SILAGHI-DUMITRESCU, C.A GRUIAN, C. PUSCAS, A. SIMON, E. FISHER-FODOR, V. AL. TOMA, A. FARCAS, I. ROMAN, V.-F. SCURTU, AMR A.A. ATTIA, G. DAMIAN

\section{INTRODUCTION}

Site-directed spin labeling (SDSL) in combination with EPR spectroscopy is a complementary method to $X$ ray crystallography and NMR spectroscopy, widely used for monitoring the structure and dynamics of the proteins.[1] The paramagnetic center (spin label) is typically added specifically at cysteine residues - native as well as purposefully introduced by sitedirected mutagenesis.[2] The most used spin labelled for this purpose is methanethiosulfonate (MTS), due to its small volume and its sulfhydryl specificity. $[1,3]$ Continuous wave EPR spectroscopy (CW) offers information about the solvent accessibility of the spin labels (and implicitly of the amino acid where they are attached), their mobility, polarity of the surroundings, as well as on intra and intermolecular distances between two spin labels or between spin labels and any other paramagnetic centers situated at a distance below $2 \mathrm{~nm}$.[1,4-6] Complementary to this, pulse EPR can detect inter-spin distances between 2 and 8.[1,7-11]

Bovine hemoglobin $(\mathrm{Hb})$ has two native cysteines in the $\beta$ chains, both accessible for spin labeling. The crystal structure of the protein displays a distance of approximately $21 \AA$ between the two $\beta-93$ positions within the tetramer.[2,12-15] Bovine $\mathrm{Hb}$ is often cited as a promising starting material for $\mathrm{Hb}$-based artificial oxygen carriers. The synthetic strategies to this goal often entail increasing the apparent molecular weight, such as by polymerization of with glutaraldehyde or copolymerization with an antioxidant/protective molecule (ranging from small organics to proteins such as serum albumin).[16-20] The present study reports an application of EPR in combination with SDSL on bovine $\mathrm{Hb}$ and on two blood substitute candidates - a version obtained by simple polymerization of $\mathrm{Hb}$ with glutaraldehyde and a copolymer of $\mathrm{Hb}$ with BSA, both of which have previously been extensively tested as potential blood substitute materials. [16-19,21] The structural information derived from such measurements is the more useful when one considers their inherent heterogeneity, which makes them much less amenable to traditional methods such as x-ray crystallography.

\section{RESULTS AND DISCUSSIONS}

\section{Continuous-wave EPR spectra of blood spin-labelled blood substitute candidates}

Bovine hemoglobin has a native cysteine accessible for spin labels in position $\beta-93$, which was labelled with MTS. The crystal structure of the protein displays a distance of approximatively $21 \AA$ between the two $\beta-93$ positions within the tetramer. (Figure 1) 


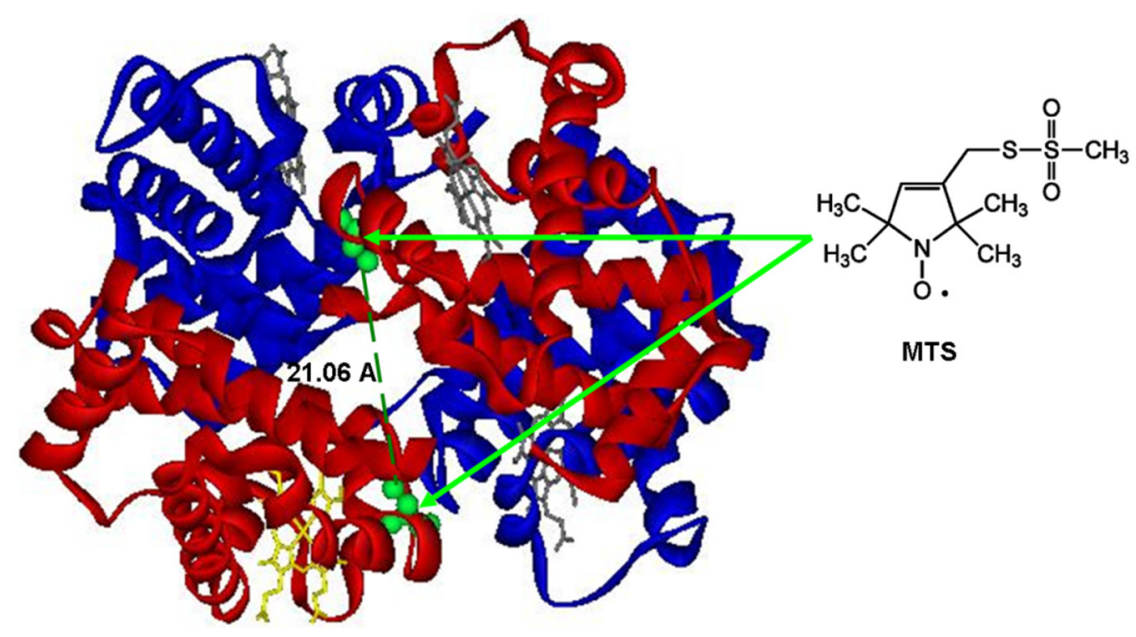

Figure 1. Structure of hemoglobin (2QSS from Protein Data Bank). The a-chains are colored in blue and the $\beta$-chains are colored in red; heme group are indicated in stick representation and cysteine-93 from the both $\beta$-chains are shown in green ball, with dashed lines between them.

Figure 2 shows the EPR spectra of native, polymerized and copolymerized hemoglobin labelled with MTS, in buffer. The cw-EPR spectra of labelled proteins have two components, associated with different mobility states of the attached spin labels. The immobile component is associated with a fraction of spin labels engaged in secondary and tertiary interactions that restrict their reorientation freedom, while the mobile component (M) corresponds to the signal provided by spin labels that have less constrains in their surroundings and that are exposed to aqueous environment. The populations corresponding to these two states are in thermodynamic equilibrium with the mobile phase more pronounced in solution.[1,22] The two spectral components are clearly visible in the polymerized and copolymerized hemoglobin, showing an increase of the immobilization component following the glutaraldehyde polymerization procedure. When BSA is added, the protein immobilization is even more pronounced, and it also affects the mobile component of the spectrum. This may be interpreted as proof that that hemoglobin molecules are surrounded by BSA in the copolymer - hence a true heteropolymer, not a mixture or aggregation of a BSA polymer with $\mathrm{aHb}$ polymer. This assumption is, as seen below, supported by the pulse DEER measurements. 


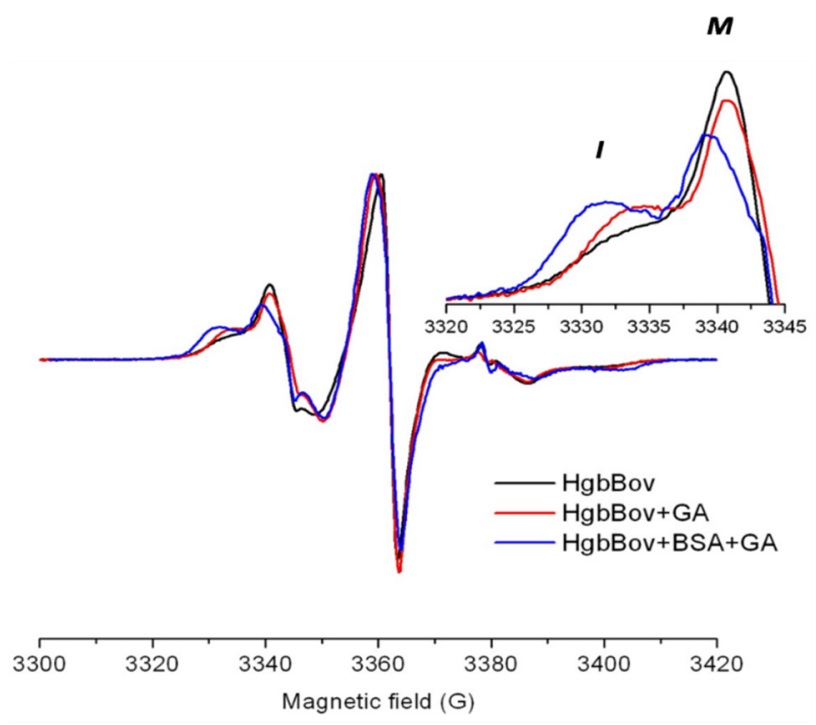

Figure 2. Superposed $\mathrm{cW}$-EPR spectra recorded at room temperature for native hemoglobin, polymerized with glutaraldehyde (GA) and copolymerized with BSA and labelled with MTS. The spectra were recorded in PBS, pH 7.4.

\section{DEER experiments}

The DEER analyses of the samples show a high modulation depth of the DEER traces (Figure 3a), indicating the dipolar interaction of a considerable number of spin labels. The distance distribution obtained for all three samples (native, polymerized and polymerized hemoglobin) exhibits a peak at $28.6 \AA$, slightly longer than the Cys---Cys distance seen within the $\mathrm{Hb}$ tetramer in the X-ray structure $(21 \AA)$. This difference is caused likely by the dynamics of the protein domains, as well as by added size of the spin label. Interestingly, a second peak situated at a distance longer than the first peak, at $44 \AA$, appears in the distance distribution curve after the polymerization of hemoglobin. This peak reflects the interaction of spin labels of neighboring hemoglobin molecules within the formed cluster; Figure 4 reveals that hemoglobin tetramers can indeed be organized at close distance, amenable for crosslinking with glutaraldehyde, where inter-protein Cys-Cys distances are in good agreement with the DEER data. In the Hb-BSA copolymer, this 44- $\AA$ distance peak does not appear anymore, suggesting that in this case the hemoglobin molecules are surrounded by BSA within the formed cluster, so that spin labels from neighboring $\mathrm{Hb}$ are not within the (maximum) $8 \mathrm{~nm}$ range of a DEER measurement. Such data allow one to get insight on the structure of the polymer and copolymer, which, considering their inherent heterogeneity is very difficult to obtain by traditional methods such as x-ray crystallography. 


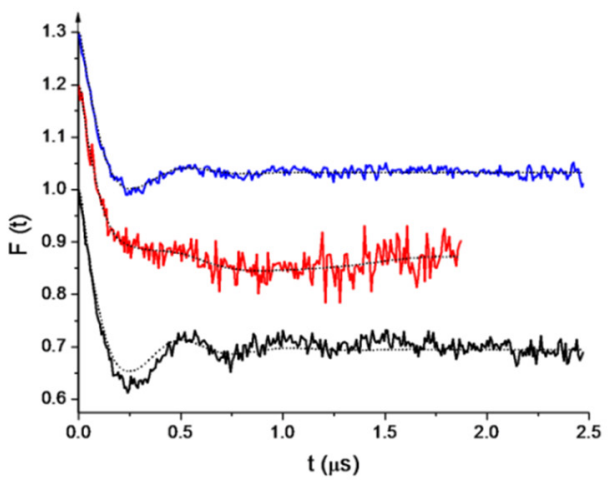

(a)

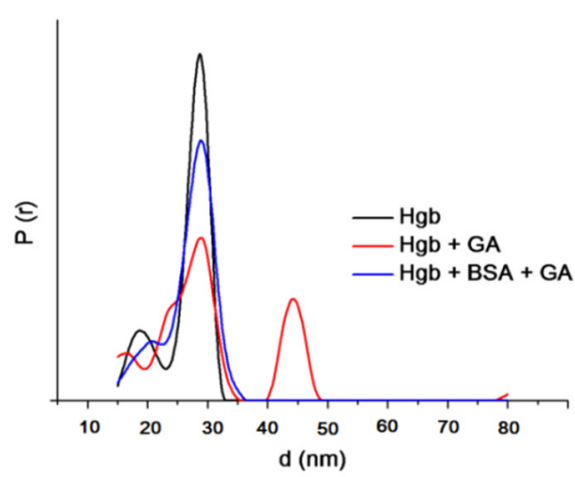

(b)

Figure 3. DEER characterization of MTS) spin-labelled of native hemoglobin and polymerized and copolymerized one: a) background corrected dipolar evolution data; b) data analysis performed by Tichonov regularization.

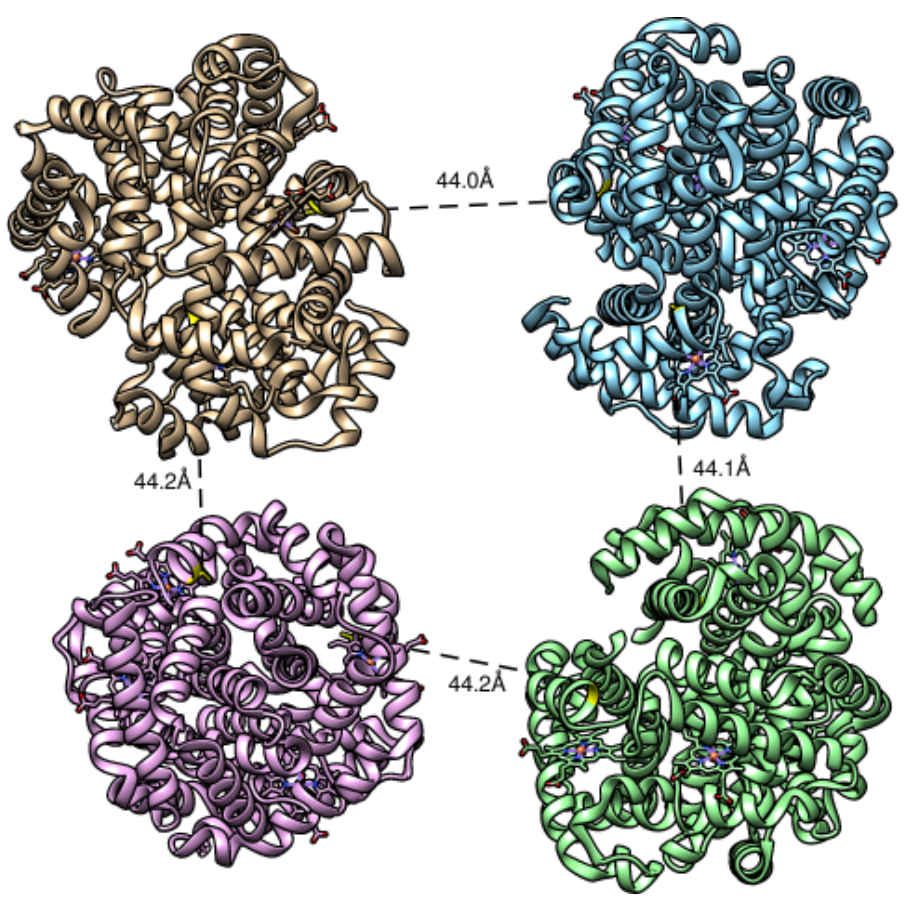

Figure 4. Evaluation of relative distances between cysteines in glutaraldehyde polymerized hemoglobin. 
R. SILAGHI-DUMITRESCU, C.A GRUIAN, C. PUSCAS, A. SIMON, E. FISHER-FODOR, V. AL. TOMA, A. FARCAS, I. ROMAN, V.-F. SCURTU, AMR A.A. ATTIA, G. DAMIAN

\section{Cell cultures}

Samples containing native (simple tetrameric) spin-labelled $\mathrm{Hb}$ were mixed with $E$. coli cells at various different ratios that were chosen to be similar to those that might occur between blood substitutes and human cells during an actual transfusion experiment. EPR spectra were recorded immediately after mixing, as well as after 1 and 4 days, respectively. Figure 5 shows illustrative spectra; apparently, when $\mathrm{Hb}$ is in contact with cells, the signal intensity decreases; nevertheless, it is clearly detectable even after 24 hours.

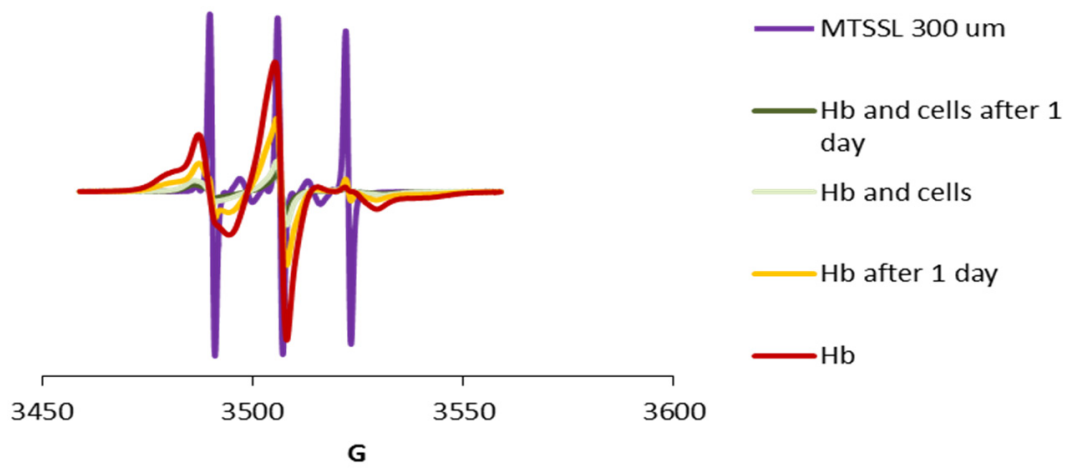

Figure 5. EPR spectra of the spin label and spin-labeled $\mathrm{Hb}$ in the presence of E.coli cells

$\mathrm{HB}-\mathrm{BSA}$ and $\mathrm{Hb}-\mathrm{HSA}$ (bovine hemoglobin co-polymerized with bovine and human serum albumins, respectively) were then tested in similar protocols to those presented above for native $\mathrm{Hb}$, cf. Figure 6. As expected, the lineshapes of both albumin copolymers are very similar to those of the nonpolymerized native $\mathrm{Hb}$ - though with some apparent loss in mobility in the spin label, as expected in a polymer versus the "monomer". The signal is clearly detectable even after $48 \mathrm{~h}$. In the presence of cells, a severe reduction of the immobile component is also noticeable from the shape of the spectra at 3480 $\mathrm{G}$. These data appear to suggest that the copolymer with BSA is more stable in the environment outside the cells compared to the copolymer with HSA. UVvis measurements of supernatant and cells separately after exposure to $\mathrm{Hb}$ and its copolymerized species were also recorded after mixing and in time, at 24 and 48 hours. As shown in Figure 7, the characteristic Soret band of $\mathrm{Hb}$ is intact and restricted to the supernatatnt - suggesting that the copolymers do not enter or adhere to the surface of the cells. 


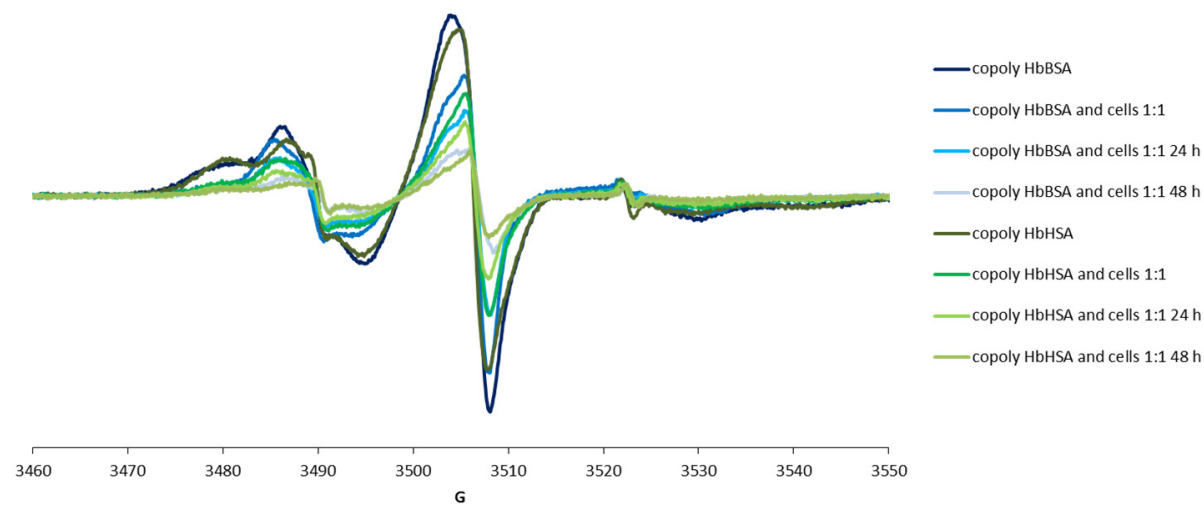

Figure 6. EPR spectra of the two Hb-albumin complexes in the presence of E.coli cells in time.
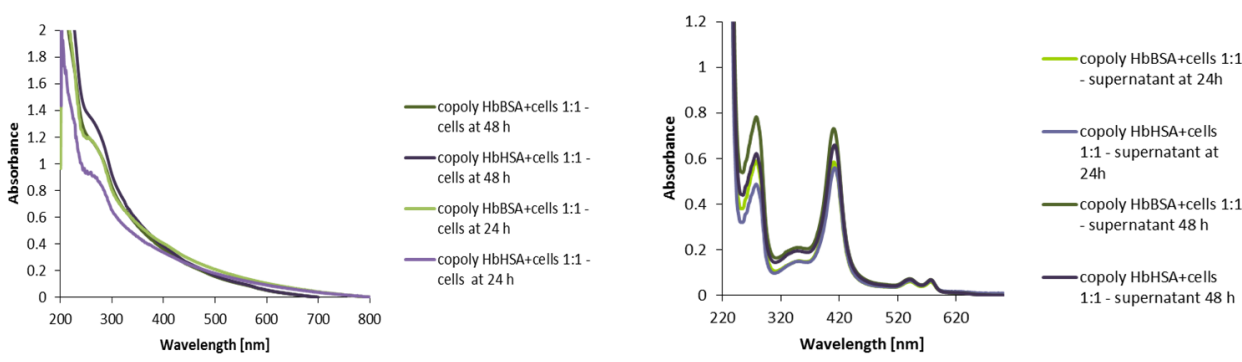

Figure 7. UV-vis spectra of the E.coli cell culture (left) and the supernatants (right) at 24 and 48 hours after exposure to both $\mathrm{Hb}$ copolymers.

HUVEC line cells are regular cells which exist in veins collected from the umbilical cord and they would be the first to be affected if the products enters the bloodstream when tested in vivo. Therefore, EPR spectra were also collected on such cell cultures after inoculation with the Hb-BSA copolymer. Figures 8 and 9 show that there is only insignificant trace of the spin label inside these cells, whereas the proteins are detected in the surrounding environment. The effect of the contact of these artificial hemoglobins with human cells at 24 and 48 hours suggests the reduction of the disulfide bond between the proteins and the spin label, which can be clearly seen by the line shape of the spectra which are reminiscent of the free, non protein-bound, spin label. 

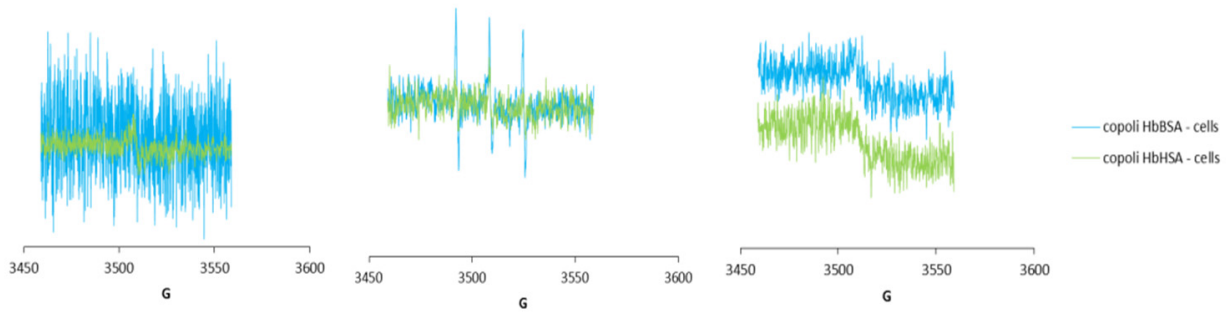

Figure 8. EPR spectra of the HUVEC cellular suspension in time at the moment of mixing (left), at 24 (center) and 48 hours (right).
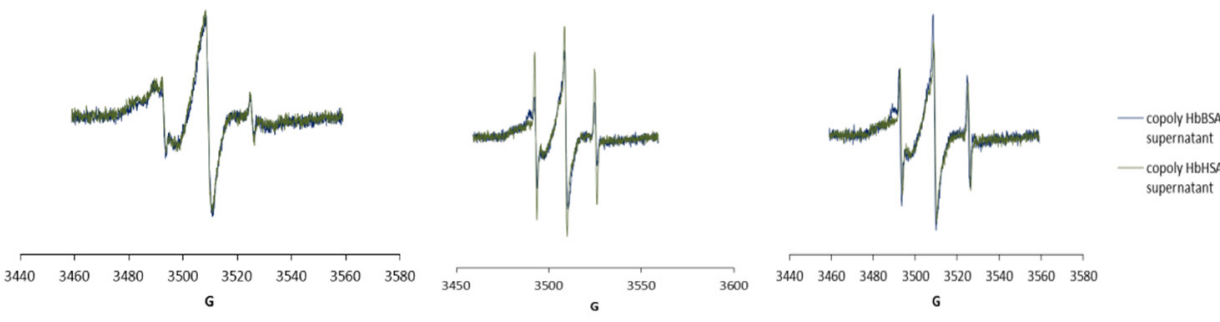

Figure 9. EPR spectra of the survival of the bound spin label in the supernatant in time - at the moment of mixing (left), at 24 (center) and 48 hours (right)

\section{In vivo results}

EPR spectra collected on the blood of Wistar rats at 10 minutes, 2 hours and 24 hours after injection with the $\mathrm{Hb}$ polymer are shown in Figure 10. The intensity of the EPR signal is very low even at 10 minutes after injection, when the physiological mechanisms would not have had time to remove the product from the bloodstream, but mostly to distribute it homogeneously in the blood vessels. Also, the line shapes are typical of the free form of the spin label. Overall, these data lead to the conclusion that $\mathrm{Hb}$ bound to MTSSL has a very short lifetime when exposed to human living systems and further in vivo investigation of $\mathrm{HBOC}$ with this spin label is not feasible. Possible alternatives with spin labels which can form a more stable adduct with globins (e.g., involving iodoacetamide) are currently considered. 

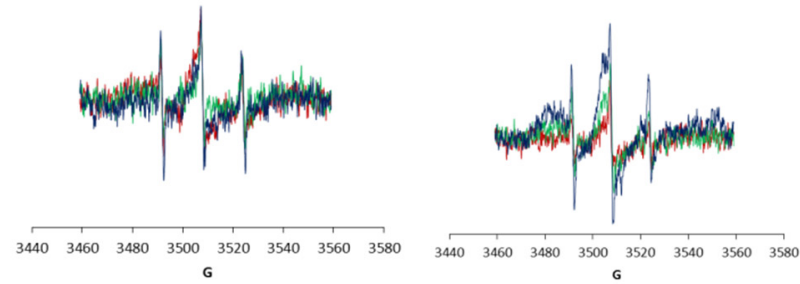

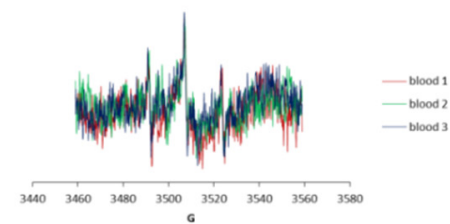

Figure 10. EPR spectra of the Hb polymer at 10 minutes (left), 2 hours (center) and 24 hours (right) after its injection in rats (3 experiments).

\section{CONCLUSIONS}

Three hemoglobin $(\mathrm{Hb})$ based $\mathrm{HBOC}$ candidates $(\mathrm{Hb}$ polymerized with glutaraldehyde, $\mathrm{Hb}$ copolymerized with $\mathrm{BSA}$, and $\mathrm{Hb}$ copolymerized with HSA) were investigated using EPR spectroscopy combined with site-directed spin labeling (SDSL), a method widely used for investigating the dynamics and structure of the proteins. The spin labeling procedure entails the specific addition of MTSSL to a site at the two native $\beta 93$ cysteines residues in the hemoglobin tetramer.

These products were then tested in vitro by exposing them to living cells, Escherichia coli cultures and human umbilical vein endothelial cells (HUVEC). Also, in vivo tests on animals were performed which provided information about the lifetime of the copolymer into the circulatory system, and the undergone structural changes. The $\mathrm{Hb}$ (co)polymers are stable in the investigated in vitro and in vivo conditions; however, their spin labels were only stable when exposed to $E$. coli cells. In human cell cultures and in vivo the spin labels were essentially depleted immediately upon exposure (e.g., 10 minutes). This suggests that spin labeling of $\mathrm{HBOC}$ for the purpose of in vivo monitoring may require more robust attachment procedures than with MTSSL.

\section{EXPERIMENTAL SECTION}

Hemoglobin and its (co)polymers with glutaraldehyde and albumin were obtained and characterized as previously described.[16,17] Structural protein analysis and visualization was performed within the Chimera software package.[23] 
R. SILAGHI-DUMITRESCU, C.A GRUIAN, C. PUSCAS, A. SIMON, E. FISHER-FODOR, V. AL. TOMA, A. FARCAS, I. ROMAN, V.-F. SCURTU, AMR A.A. ATTIA, G. DAMIAN

Hemoglobin spin labeling. The proteins were incubated with $10 \mathrm{mM}$ dithiothreitol (DTT) at $4^{\circ} \mathrm{C}$ for 2 hours to break the disulfide bridges. Buffer condition were $100 \mathrm{mM} \mathrm{KCl}, 50 \mathrm{mM}$ Tris-DCl (pH 7.5) and $5 \mathrm{mM} \mathrm{MgCl}_{2}$ in $\mathrm{D}_{2} \mathrm{O}$. Afterwards, in order to remove the DTT and to replace the acidic conditions, the samples were washed by repeated dilution step with phosphate buffer ( $\mathrm{pH}$ 8.2), using centrifugal filter units with $30 \mathrm{kDa}$ molecular weight cutoff. Afterwards, the protein solutions were incubated with ten-fold molar excess of MTSSL overnight. The excess of spin labels was removed by consecutive washing and centrifugation steps. Labeling efficiency was estimated to be $90 \%$. Hb was subsequently (co)polymerized as previously described,[19] and prepared for in vitro and in vivo experiments as a stock solution of $1 \mathrm{mM}$ in phosphate buffer, saline (PBS).

Cw-EPR measuremens. The room temperature X-band cw-EPR measurements were conducted on a home-made EPR spectrometer equipped with a Bruker dielectric resonator. Glass capillaries of $0.9 \mathrm{~mm}$ inner diameter were filled with a sample volume of $15 \mu \mathrm{L}$, sufficient for a total active resonator volume of $10 \mu \mathrm{L}$. The microwave power was set to $1.0 \mathrm{~mW}$, the B-field modulation amplitude was $0.15 \mathrm{mT}$.

DEER measurements. DEER measurement were recorded at a Xband frequency with a Bruker Elexsys 580 spectrometer equipped with a Bruker Flexline split-ring resonator ER4118xms3 and a continuous flow helium cryostat ESR900 (Oxford Instruments) controlled by an Oxford Intelligent temperature controller ITC 503S. Prior to freezing the protein in $3 \mathrm{~mm}$ inner diameter EPR tubes, $20 \%$ (v/v) glycerol was added to each sample in order to increase viscosity. All data were collected at $50 \mathrm{~K}$ following the four-pulse DEER sequence. The total measurement time for each sample was 8-24 h. Data analysis was performed with DeerAnalysis2011/2013.[22]

\section{Cell culture and in vivo experiments}

Initial experiments were made with the $E$. coli strain BL 21 (DE3), freshly cultivated on LB medium. Samples of both native (simple tetrameric) and albumin-copolymerized $\mathrm{Hb}$ were mixed with these culture cells at various different ratios chosen to be similar to those that might occur between blood substitutes and human cells during an actual transfusion experiment.

HUVEC cells were cultivated as previously described and exposed to HBOC candidates in a ratio of $1: 1(\mathrm{v}: \mathrm{v})$.

Wistar rats were selected and prepared/treated as previously described in HBOC top-up experiments; $[19,24]$ the experiments and animals welfare were conducted according to the Guide for the Care and Use of Laboratory Animals $8^{\text {th }} \mathrm{ed}$. (Department of Health Education, and Welfare, National Institute 
of Health, 1996), and followed the guidelines of the Directive 2010/63/UE of the European Parliament and of the Council with ethical approvals. The animal testing and experiments were approved by the Ethics Committee and Animal Protection for experiments from the Institute of Biological Research, NIRDBS branch, Cluj-Napoca, Romania. (Decision 1/28.02.2013). Following injection with the HBOC candidate, blood for EPR measurements was collected at 10 minutes, 2 hours and 24 hours.

EPR measurements were performed on cell cultures and on venous blood samples collected from the rats under conditions previously described.[19]

\section{ACKNOWLEDGMENTS}

CB thanks to the financial support of the Sectorial Operational Programme for Human Resources Development 2007-2013, co-financed by the European Social Fund, under the project POSDRU/159/1.5/S/132400 - "Young successful researchers - professional development in an international and interdisciplinary environment".

\section{REFERENCES}

1. Klare, J.P.; Steinhoff, H.J. Photosynth. Res. 2009, 102, 377-390.

2. Horváth, L.I.; Török, M.; Hideg, K.; Dux, L. J. Mol. Recognit. 1997, 10, 188193.

3. Berliner, L.J.; Grunwald, J.; Hankovszky, H.O.; Hideg, K. Anal. Biochem. 1982, 119, 450-455.

4. Hubbell, W.L.; Cafiso, D.S.; Altenbach, C. Nat. Struct. Biol. 2000, 7, 735-739.

5. Banham, J.E.; Baker, C.M.; Ceola, S.; Day, I.J.; Grant, G.H.; Groenen, E.J. J.; Rodgers, C.T.; Jeschke, G.; Timmel, C.R. J. Magn. Reson. 2008, 191, 202-218.

6. Grote, M.; Bordignon, E.; Polyhach, Y.; Jeschke, G.; Steinhoff, H.J.; Schneider, E. Biophys. J. 2008, 95, 2924-2938.

7. Borbat, P.P.; Freed, J.H. Chem. Phys. Lett. 1999, 313, 145-154.

8. Pannier, M.; Veit, S.; Godt, A.; Jeschke, G.; Spiess, H.W. J. Magn. Reson. 2000, 142, 331-340.

9. Schiemann, O.; Prisner, T.F. Q. Rev. Biophys. 2007, 40, 1-53.

10. Klare, J.P. Biol. Chem. 2013, 394, 1281-1300.

11. Jeschke, G. Annu. Rev. Phys. Chem. 2012, 63, 419-446.

12. Gruian, C.; Steinhoff, H.J.; Simon, S. Studia UBB Chemia 2011, 71-81.

13. Gruian, C.; Vulpoi, A.; Steinhoff, H.J.; Simon, S. J. Mol. Struct. 2012, 1015, 20-26. 
R. SILAGHI-DUMITRESCU, C.A GRUIAN, C. PUSCAS, A. SIMON, E. FISHER-FODOR, V. AL. TOMA, A. FARCAS, I. ROMAN, V.-F. SCURTU, AMR A.A. ATTIA, G. DAMIAN

14. Takacs, I.M.; Mot, A.; Silaghi-Dumitrescu, R.; Damian, G. J. Mol. Struct. 2014, 1073, 18-23.

15. Takacs, M.I.; Mot, A.; Silaghi-Dumitrescu, R.; Damian, G. Studia UBB Chemia 2013, 58, 61-69.

16. Iacob, B.; Deac, F.; Cioloboc, D.; Damian, G.; Silaghi-Dumitrescu, R. Artif. Cells Blood Substitutes Biotechnol. 2011, 39, 293-297.

17. Scurtu, F.; Zolog, O.; lacob, B.; Silaghi-Dumitrescu, R. Artif. Cells Nanomedicine Biotechnol. 2014, 42, 13-17.

18. Hathazi, D.; Scurtu, F.; Bischin, C.; Mot, A.; Attia, A.; Kongsted, J.; SilaghiDumitrescu, R. Molecules 2018, 23, E350.

19. Toma, V.A.; Farcas, A.D.; Roman, I.; Sevastre, B.; Hathazi, D.; Scurtu, F.; Damian, G.; Silaghi-Dumitrescu, R. PLoS One 2016, 11, e0153909.

20. Hathazi, D.; Mot, A.C.; Vaida, A.; Scurtu, F.; Lupan, I.; Fischer-Fodor, E.; Damian, G.; Kurtz Jr., D.M.; Silaghi-Dumitescu, R. Biomacromolecules 2014, $15,1920-1927$.

21. Scurtu, V.-F.; Moţ, A.C.; Silaghi-Dumitrescu, R. Pharmaceuticals 2013, 6, 867-880.

22. Bridges, M.D.; Hideg, K.; Hubbell, W.L. Appl. Magn. Reson. 2010, 37, 363390.

23. Pettersen, E.G.; Goddard, T.D.; Huang, C.C.; Couch, G.S.; Greenblatt, D.M.; Meng, E.C.; Ferrin, T.E. J. Comput. Chem. 2004, 25, 1605-1612.

24. Toma, V.A.A.; Farcas, A.D.D.; Roman, I.; Sevastre, B.; Hathazi, D.; Scurtu, F.; Damian, G.; Silaghi-Dumitrescu, R. Int. J. Biol. Macromol. 2017, 107, 14221427. 